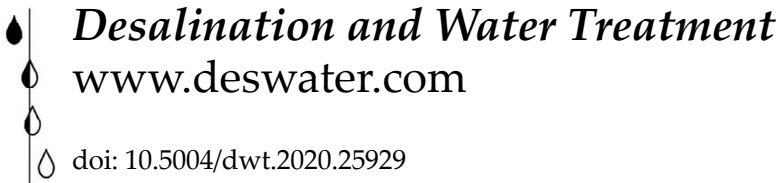

\title{
Optimization of the treatment of a real textile wastewater by coagulation- flocculation processes using central composite design
}

\author{
Dalila Sakhi ${ }^{\mathrm{a}, *}$, Abdellah Elmchaouria,*, Youness Rakhila ${ }^{\mathrm{a}}$, Meriem Abouria ${ }^{\mathrm{a}}$, Salah Souabi ${ }^{\mathrm{b}}$, \\ Mohamed Hamdanic, Amane Jada ${ }^{\mathrm{d}}$ \\ ${ }^{a}$ Laboratory of Physical Chemistry and Bioorganic Chemistry, Faculty of Sciences and Technology of Mohammedia, \\ Hassan II University, BP 146, Mohammedia, Morocco, emails: sakhi.dalila@gmail.com (D. Sakhi), elmchaouri@hotmail.fr (A. Elmchaouri), \\ younessrakhila@gmail.com (Y.Rakhila),meriemabouri@hotmail.com (M. Abouri) \\ ${ }^{b}$ Laboratory of Process Engineering and Environment, Faculty of Sciences and Technology of Mohammedia, Hassan II University, \\ Mohammedia, Morocco, email: salah.souabi@gmail.com (S. Souabi) \\ 'Laboratory of Chemistry, Department of Chemistry, Faculty of Sciences Ibn Zohr, Agadir, Morocco, \\ email: hamdani.mohamed@gmail.com (M. Hamdani) \\ ${ }^{d}$ Instituts of Materials Science of Mulhouse, Mulhouse, France, email: amane.jada@uha.fr (A. Jada)
}

Received 22 October 2019; Accepted 33 April 2020

\begin{abstract}
A B S T R A C T
The treatment of real textile wastewater by coagulation-flocculation (CF) using ferric chloride as coagulant and polymer as flocculant was optimized with the central composite design (CCD) based on response surfaces methodology. The independent variables considered were $\mathrm{pH}$, coagulant, and flocculant dose. Their effects on the treatment were evaluated by the analysis of variance. The models are validated by the comparison between the predicted and experimental values, with a coefficient of determination reached a value above $93 \%$, for all responses; removal efficiency of chemical oxygen demand (COD), biological oxygen demand $\left(\mathrm{BOD}_{5}\right)$, turbidity, and color. The graphical representations of the models in the space of the variables enable us to determine the optimal conditions, which are $\mathrm{pH}=8.1$, a dose of $\mathrm{FeCl}_{3}=0.8 \mathrm{~g} / \mathrm{L}$ and a dose of flocculant $=2.6 \mathrm{~mL} / \mathrm{L}$. Under these conditions, the removal efficiency of COD, turbidity, color, and $\mathrm{BOD}_{5}$ achieved $95 \%$, $92 \%, 96 \%$, and $60 \%$ respectively.
\end{abstract}

Keywords: Real textile wastewater; Coagulation-flocculation; optimization; Central composite design; Surface response methodology; Turbidity; $\mathrm{COD} ; \mathrm{BOD}_{5}$; Color

\footnotetext{
* Corresponding authors.
} 